SAÚDEE AMBIENTE

v.8 N.1 • Agosto/Setembro/Outubro - 2019

ISSN Digital: 2316-3798

ISSN Impresso: 2316-3313

DOI: 10.17564/2316-3798.2019v8n1p29-42 ORCID: 0000000000000

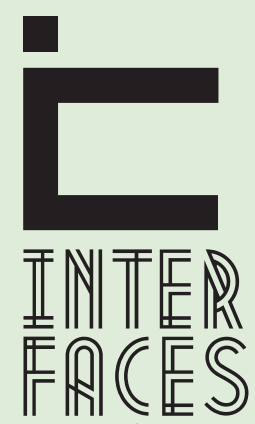

CIENTÍFICAS

\section{ELABORAÇÃO DE MICROEMULSÃO DA PLANTA MAYTENUS RIGIDA MART. [CELASTRACEAE] COM ATIVIDADE ANTIMICÓTICA}

\section{ELABORATION OF MICROEMULSION OF THE PLANT MAYTENUS RIGIDAMART. (CELASTRACEAE) WITH ANTMYYCOTIC ACTIVITY}

ELABORACIÓN DE MICROEMULSIÓN DE LA PLANTA MAYTENUS RIGIDAMART. CCELASTRACEAEJ CON ACTIVIDAD ANTIMICÓTICA
Mayara Santos Tavares ${ }^{1}$

Igor Adriano de Oliveira Reis ${ }^{2}$ Samuel Bruno dos Santos ${ }^{3}$

\section{RESUMO}

A planta Maytenus rigida tem a obtenção de cura, tratamento e prevenção de diversas doenças, tornando-se um recurso terapêutico importante para grande parte da população. 0 objeto do estudo foi a entrecasca da Maytenus rigida, onde fora realizado os extratos hidroetanólico (EHEE) e suas frações. Através dessa metodologia podemos detectar a análise das determinações quantitativas de fenóis totais e flavonóides do EHEE e suas frações. Posteriormente, submetidas à extração em etanol $90 \%$ durante 5 dias na temperatura ambiente em recipiente fechado. A entrecasca $(2,3 \mathrm{~kg})$ foi seca em estufa, a $37^{\circ} \mathrm{C}$, com renovação e circulação de ar até peso constante, porém não foram determinadas a umidade nem atividade de água, pois no processo de extração foram utilizados solventes orgânicos. Em seguida, o extrato foi filtrado e concentrado em evaporador rotatório, sob pressão reduzida a $50^{\circ} \mathrm{C}$, para eliminação do solvente e obtenção de extrato hidroetanólico da entrecasca - EHEE. Uma parte deste extrato $(250 \mathrm{~g})$ foi dissolvida em uma solução de $\mathrm{MeOH} / \mathrm{H}_{2} \mathrm{O}$ (2:3) e submetida à extração líquido-líquido com hexano, clorofórmio e acetato de etíla, visando à aquisição das frações hexânica - FHX, clorofórmica - FC, acetato de etíla - FACE e hidrometanólica FHM. $\mathrm{O}$ solvente correspondente a cada uma delas foi evaporado, a $50^{\circ} \mathrm{C}$, em condensador rotatório e ambos os solventes não foram recuperados. Destas amostras foram obtidos os rendimentos do EHEE das frações clorofórmica - FC, Fração hexânica - FHX, Fração acetato de etila - FACE e Fração hidrometanólica - FHM, respectivamente $10,00 \%, 14,08 \%, 4,72 \%, 22,28 \%$ e $19,44 \%$. Neste estudo, extratos e frações da Maytenus rigida, favorecem significativamente a viabilidade dos macrófagos em todas as concentrações testadas 30, 100, $300 \mu \mathrm{g} \cdot \mathrm{ml}^{-1}$ em comparação as células não tratadas, as quais funcionaram como controles. 


\section{PALAVRAS-CHAVE}

Extração, Fração, Microemulsão, Antioxidante, Antimicrobiano.

\section{ABSTRACT}

The plant Maytenus rigida has the achievement of cure, treatment and prevention of various diseases, making it an important therapeutic resource for a large part of the population. The object of the study was the binder of the Maytenus rigida, where the hydroethanolic extracts (EHEE) and their fractions had been carried out. Through this methodology we can detect the quantitative determinations of total phenols and flavonoids of EHEE and its fractions. Subsequently, they were extracted in $90 \%$ ethanol for 5 days at room temperature in a closed container. The bunch $(2.3 \mathrm{~kg})$ was dried in an oven at $37^{\circ} \mathrm{C}$, with air circulation and constant weight change, but the humidity and water activity were not determined, because organic solvents were used in the extraction process. The extract was then filtered and concentrated in a rotary evaporator, under reduced pressure at $50^{\circ} \mathrm{C}$, to remove the solvent and obtain hydroethanolic extract from the EHEE. A portion of this extract $(250 \mathrm{~g})$ was dissolved in a solution of $\mathrm{MeOH} / \mathrm{H}_{2} \mathrm{O}(2: 3)$ and subjected to liquid-liquid extraction with hexane, chloroform and ethyl acetate, for the hexane-FHX, chloroform-FC, ethyl acetate - FACE and hydromethanol - FHM. The solvent corresponding to each was evaporated at $50^{\circ} \mathrm{C}$ in a rotary condenser and both solvents were not recovered. From these samples, the EHEE yields of the chlorhemical fractions - FC, hexane fraction - FHX, ethyl acetate fraction - FACE and hydrometanic fraction - FHM, respectively $10.00 \%$, $14.08 \%, 4.72 \%, 22.28 \%$ and $19.44 \%$. In this study, extracts and fractions of Maytenus rigida significantly favor the viability of macrophages at all concentrations tested 30, 100, $300 \mu \mathrm{g} \cdot \mathrm{ml}^{-1}$ compared to untreated cells which functioned as controls.

\section{KEYWORDS}

Extraction, Fraction, Microemulsion, Antioxidant, Antimicrobial.

\section{RESUMEN}

La Planta, Maytenus rigida tiene la obtención de cura, tratamiento y prevención de diversas enfermedades, convirtiéndose en un recurso terapéutico importante para gran parte de la población. El objeto del estudio fue la entrecasca la Maytenus rigida donde se realizaron los extractos hidroetanólico (EHEE) y 
sus fracciones. A través de esta metodología podemos detectar el análisis de las determinaciones cuantitativas de fenoles totales y flavonoides del EHEE y sus fracciones (FACE, FHX, FHME y FC). Posteriormente, sometidas a la extracción en etanol $90 \%$ durante 5 días a la temperatura ambiente en recipiente cerrado. La entrecasca $(2,3 \mathrm{~kg})$ fue seca en invernadero, a $37^{\circ} \mathrm{C}$, con renovación y circulación de aire hasta peso constante, pero no se determinó la humedad y ni actividad de agua, pues en el proceso de extracción se utilizaron disolventes orgánicos. A continuación, el extracto fue filtrado y concentrado en evaporador rotatorio, bajo presión reducida a $50^{\circ} \mathrm{C}$, para eliminación del solvente y obtención de extracto hidroetanólico de la entreca - EHEE. Una parte de este extracto $(250 \mathrm{~g})$ fue disuelta en una solución de $\mathrm{MeOH} / \mathrm{H}_{2} \mathrm{O}$ (2:3) y sometida a la extracción líquido-líquido con hexano, cloroformo y acetato de etíla, buscando la adquisición de las fracciones hexán- fica - FHX, clorofórmica - FC, acetato de etíla - FACE e hidrometanólica - FHM. El solvente correspondiente a cada una de ellas fue evaporado, a $50^{\circ} \mathrm{C}$, en condensador rotatorio y ambos solventes no fueron recuperados. De estas muestras se obtuvieron los rendimientos EHEE de fracciones de cloroformo - FC, fracción de hexano - FHX, fracción de acetato de etilo - FACE y fracción hidrometanólica - FHM, respectivamente 10,00\%, 14,08\%, 4,72\%, 22,28 \% y $19.44 \%$. En este estudio, extractos y fracciones de Maytenus rigida, favorecen significativamente la viabilidad de los macrófagos en todas las concentraciones probadas 30, 100, 300 ug. $\mathrm{ml}^{-1}$ en comparación con las células no tratadas que funcionaron como controles.

\section{PALABRAS CLAVE}

Extracción, Fracción, Microemulsión, Antioxidante, Antimicrobiano.

\section{INTRODUÇão}

As plantas são utilizadas pela medicina popular há muito tempo com a finalidade de tratamento e prevenção de diversas doenças, tornando-se um recurso terapêutico importante para grande parte da população (REINALDO et al., 2015). Desta forma, produtos naturais, especialmente os originados a partir de plantas, continuam sendo excelentes fontes de moléculas bioativas. Apresentam uma diversidade biológica que está relacionada à variabilidade química, ou seja, os organismos estão sujeitos a interações metabólicas e ambientais, produzindo sempre novas moléculas (MOLINARI, 2009).

A forma de retirada e obtenção destes compostos presentes nas matrizes das células vegetais é através dos métodos extrativos. A extração é a primeira etapa dos estudos com plantas medicinais, sendo de extrema importância nos resultados obtidos, pois interfere nos testes qualitativos e quantitativos dos metabólitos, exercendo papel fundamental no resultado final do processamento de produtos farmacêuticos e alimentícios (AZMIR et al., 2013). Esta etapa pode sofrer interferência de vários fatores como temperatura, tempo de extração, solvente, parte da planta utilizada, razão de solvente e volatilidade (AZMIR et al., 2013). 
Vale ressaltar que o interesse das plantas como recurso terapêutico está além do intuito de desenvolver medicamentos fitoterápicos, relacionando-se também ao ato de registrar o material vegetal de acordo com sua utilização dentro de uma comunidade, sua função no contexto da medicina tradicional, bem como a incorporação do material na rede de saúde pública, principalmente na atenção primária à saúde no setor do Sistema Único de Saúde (SUS) (BITTENCOURT et al., 2002; PIRES et al., 2014).

No intuito de contribuir para o estudo farmacológico, este trabalho tem como objetivo produzir as microemulsões e a preparação dos extratos da planta Maytenus rigida Mart. (Celastraceae), com a finalidade de encontrar atividade antimiótica. As microemulsões apresentam um grande potencial também para as vias vaginais e retais, principalmente para veicular fármacos lipofílicos como antibióticos, esteroides e hormônios devido a sua alta capacidade de solubilização das drogas, aumento da absorção e o melhoramento da potência clínica. Entretanto, o uso de uma microemulsão (ME) por essas vias implica em rigorosa atenção com relação a sua ausência de toxicidade e sua biodisponibilidade (D'CRUZ; UCKUN, 2001). Uma alternativa terapêutica viável para o tratamento de infecções fúngicas (candidíases) vaginais é a utilização de uma ME bicontínua (semelhante a um gel) contendo fluconazol. Este produto não apresentou nenhuma irritação vaginal em coelhos, mostrando-se bastante tolerável (BACHHAV; PATRAVALE, 2009). Ensaios farmacológicos com extratos desta espécie comprovaram atividade antinociceptiva (DIAS et al., 2007), estimulante do Sistema Nervoso Central (OMENA, 2007), antioxidante (ESTEVAM et al., 2009), antidiarreica, antiinflamatória, antiulcerogênica e antiespasmódica (SANTOS et al., 2007). Por isso a preocupação do estudo da planta, sempre visando o melhor, na qual a planta pode ser a solução da cura de várias doenças nos próximos anos.

\section{MATERIAL E MÉTODOS}

\subsection{PREPARO E FRACIONAMENTO DO EXTRATO HIDROETANÓLICO DA ENTRECASCA DE M. RIGIDA.}

A entrecasca $(2,3 \mathrm{~kg})$ foi seca em estufa, a $37^{\circ} \mathrm{C}$, com renovação e circulação de ar até peso constante e sua umidade final não foi verificada. Logo após, foram reduzidas a pó utilizando-se um moinho de facas, que executa a moagem de amostras secas, por meio de um motor potente responsável por movimentar as lâminas de facas, que irão atuar dentro de uma câmara para atingir granulometrias menores. Posteriormente, submetidas à extração em etanol $90 \%$ durante 5 dias na temperatura ambiente em recipiente fechado. Em seguida, o extrato foi filtrado e concentrado em evaporador rotatório, sob pressão reduzida (pressão negativa) a $50^{\circ} \mathrm{C}$ para eliminação do solvente e obtenção de Extrato Hidroetanólico da Entrecasca - EHEE. Uma parte deste extrato $(250 \mathrm{~g})$ foi dissolvida em uma solução de Metanol - $\mathrm{MeOH} / \mathrm{H}_{2} \mathrm{O}$ (2:3) e submetida à extração líquido-líquido com Hexano, Clorofórmio e Acetato de Etíla, visando à aquisição das Frações Hexânica - FHX, Clorofórmica - FC, Acetato de Etíla - FACE e Hidrometanólica - FHM. O solvente correspondente a cada uma das frações foi evaporado a $50^{\circ} \mathrm{C}$ em condensador rotatório, sem recuperação dos solventes. Todos os solventes utilizados eram PA, com exceção da mistura na proporção duas partes de metanol PA em três partes de água destila- 
da. Destas amostras foram obtidos os rendimentos dos extratos que correspondem ao Extrato Hidroetanólico da Entrecasca - EHEE, das Frações Clorofórmica - FC, Frações Hexânica - FHX, Acetato de Etíla - FACE e Hidrometanólica - FHM, respectivamente 10,00\%, 14,08\%, 4,72\%, 22,28\% e 19,44\%.

\subsection{ANÁLISE DE CITOTOXICIDADE IN VITRO}

Os macrófagos (J774) foram cultivados em meio RMPI 10\% suplementado com SFB (Soro Fetal Bovino) que contém ácidos graxos, fatores de crescimento, aminoácidos e vitaminas, com finalidade de promover o crescimento das células. 0 meio foi colocado em câmara úmida a $37^{\circ} \mathrm{C} \mathrm{com} 5 \%$ de $\mathrm{CO}_{2}$, sendo a viabilidade das células $\mathrm{J} 774$ ( $2 \times 10^{4}$ células) avaliada em triplicata após 24 horas de exposição contínua ao EHEE FAE, FC, FHX e FHM de M. rigida e medida através do ensaio colorimétrico de redução do reagente MTT (3-(4,5-dimetiltiazol-2yl)-2,5-difenil brometo de tetrazolina) a formazan (MOSMANN, 1983).

De acordo com este ensaio, a quantidade de formazan produzido é proporcional ao número de células viáveis. Após a aderência celular em placa de 96 poços, o meio de cultura foi substituído por 200 $\mu \mathrm{L}$ de meio de cultura contendo os extratos e frações diluídos em DMSO (0,5\%) (dimetilsulfóxido), nas concentrações de 10, 50 e $100 \mu \mathrm{g} \cdot \mathrm{mL}^{-1}$, e em seguida, as placas foram incubadas por 24 horas. Decorrido este tempo, o meio de cultura foi substituído por $200 \mu \mathrm{L}$ de solução corante MTT a 0,5 mg.mL-1, previamente filtrado em membrana milipore de $0,22 \mu \mathrm{m}$.

Diante disso, as placas foram incubadas por $3 \mathrm{~h}$, o suficiente para que ocorresse a redução do MTT a formazan. Após este período, todo o sobrenadante foi cuidadosamente aspirado e $200 \mu \mathrm{L}$ de DMSO foram adicionados em cada poço para a solubilização do formazan. Para análise, os resultados foram normalizados de acordo com a equação:

$\%$ VC $=[$ DO (células tratadas) DO (branco)/DO (controle) DO (branco) $] \times 100$

VC corresponde à viabilidade celular e DO refere-se à densidade ótica.

\subsection{TESTE DE DIFUSÃO EM ÁGAR}

Para realização dos testes pelo método de BAUER et al. (1966), culturas overnight $\left(35^{\circ} \mathrm{C} \pm 2\right)$ em $5 \mathrm{~mL}$ de caldo tripticase soja (TSB) foram ajustadas para padrão 0,5 de Mac Farland (concentração de $1,6 \times 10^{16} \mathrm{UFC} / \mathrm{ml}$ ). Foi utilizado inóculo em um volume de $100 \mu \mathrm{L}$ do tubo em concentração padrão, sendo inoculados em placas de Petri contendo $4 \mathrm{~mm}$ ágar Sabouraud dextrose (pH 7,2-7,4) previamente solidificado e semeado usando alça de Drigalsky.

Subsequentemente, discos de papel-filtro ( $6 \mathrm{~mm}$ de diâmetro) impregnados com $20 \mu \mathrm{L}$ do extrato vegetal em diferentes concentrações foram acondicionados sobre a superfície do meio contendo os microrganismos. Os solventes, bem como os diluentes utilizados na dissolução dos extratos, foram usados como controle negativo (CLSI, 2003). Como controle positivo foram utilizados os antifúngico cetoconazol 10 - $120 \mu \mathrm{g} \cdot \mathrm{mL}^{-1} \mathrm{com}$ atividade conhecida para cepas padrão ATCC (Cladosporium cladosporoides, Aspergilus brasiliensis, Cryptococcus albidus, Candida albicans e Aspergillus niger). 
A atividade antifúngica foi avaliada pela mensuração dos halos de inibição, em milímetros. Para a interpretação dos resultados foram seguidas as recomendações do Clinical and Laboratory Standards Institute (CLSI 2004), no qual os halos de inibição formados são comparados com a tabela de referência, sendo os microrganismos classificados como resistente (zona de inibição inferior a $8 \mathrm{~mm}$ ), intermediário (de 9 a $15 \mathrm{~mm}$ ) e sensível (15 a 25mm).

\subsection{MICROEMULSÕES}

A FHX proveniente do EHEE da M. rigida foi selecionada para produção de microemulsão, dada a riqueza de terpenos, flavonoides, flavonóis, taninos e xantonas presentes, que apresentam atividades biológicas. A fração FHX foi a que apresentou melhor resultado da atividade antimicrobiana (MARTUCCIELLO et al., 2010). Para a seleção da formulação da microemulsão, o primeiro ponto foi escolher, em termos de transparência, homogeneidade e isotropia óptica, a partir do Diagrama de fases pseudoternário (DFPT). Essa escolha mostrou uma formulação que tem como primeira fase uma solução de tampão fosfato pH 7,4 (68,0\%), e como a segunda Tween 80 (12,3\%) e ácido oleico (19,7\%).

A primeira e segunda fases foram agitadas magneticamente e separadamente, por 2 e 3 minutos, respectivamente. A produção final da microemulsão foi concluído por mistura de ambas as fases, seguindo ao processo de sonicação (1,5 min) e banho de ultrassom (3 min) (três ciclos), obtendo assim, uma microemulsão verdadeira (SILVEIRA, 2009).

A preparação dos extratos microemulsionados (MFHX) utilizados nos ensaios realizou-se por meio de incorporação direta do extrato seco hexânico de M. rigida nas microemulsões, nas concentrações de 5 e $10 \mathrm{mg} \cdot \mathrm{mL}^{-1}$, em ambiente com temperatura controlada a $25^{\circ} \mathrm{C}$, por período que variou de $10 \mathrm{a}$ 30 minutos, sob agitação magnética e lavadora ultrassônica (de 2 a 5 minutos).

Imediatamente após o termino da homogeneização, o extrato microemulsionado foi centrifugado e retirados $100 \mu \mathrm{L}$ do sobrenadante e solubilizado em etanol (diluídos 1:1000), sendo realizadas leituras espectrofotométricas no comprimento de onda de $279 \mathrm{~nm}$. A partir dos valores da absorbância foram determinadas as concentrações do MFHX que realmente foram incorporadas na microemulsão (CERA, 2001). Todos os MFHX foram esterilizados por filtração (filtros com poros de $0,22 \mu \mathrm{m})$.

\subsection{CARACTERIZACĢ̃O DAS MICROEMULSÕES}

A identificação de isotropia das formulações foi realizada por Microscopia de Luz Polarizada (MLP). Uma gota de cada amostra (MV e MFHX 10\%) foi transferida para uma lâmina de vidro, coberta por uma lamínula, posteriormente analisada sobre luz polarizada, depois de percorrido o tempo mínimo de 5 dias para o equilíbrio das formulações. Foi utilizado um microscópio Olympus BX-51 equipado com câmera digital LC Color Evolution (PL-A662) e Software analisador de Imagem PixeLINK, no Laboratório Multiusuário do Departamento de Física da Universidade Federal de Sergipe. 


\subsection{DETERMINAÇÃO DO PH}

Para determinação do $\mathrm{pH}$ das formulações MFHX 10\% e MV foi utilizado um potenciômetro digital Phtek PH 3B com eletrodo de vidro e sensor de temperatura, previamente calibrado com soluções tampão pH 4,0 e 7,0 a $25 \pm 0,5^{\circ} \mathrm{C}$ (MEHTA et al., 2007). Neste sentido, o referido eletrodo foi diretamente introduzido nos sistemas, sem qualquer diluição. Os resultados foram expressos como a média \pm desvio padrão de três determinações.

\section{RESULTADOS E DISCUSSÃO}

Compostos com atividade antimicrobiana com efeitos adversos menos graves que os atuais fármacos são ativamente procurados, principalmente aqueles compostos com um espectro de atividade complementar aos quimioterápicos já existentes. 0 método para análise antimicrobiana utilizado foi o da difusão. Neste método os extratos em pesquisa são colocados num reservatório (disco de papel, cavidade no meio de cultura ou cilindro sobre a superfície), em contato com o meio de cultura sólido, inoculado com o microrganismo. Após o tempo de incubação, mede-se o diâmetro ou halo de inibição, a informação obtida é qualitativa, útil para estabelecer a sensibilidade do microrganismo (SANTOS et al., 2011).

Segundo SILVEIRA et al. (2009), o método de difusão em disco se baseia na difusão radial das substâncias e a possível presença de partículas em suspensão na amostra a ser testada não interfere na difusão da substância antimicrobiana no ágar, o que torna este método adequado para testar a difusão de substâncias em extratos etanólicos de plantas. Adotou-se como critério de suscetibilidade o padrão sugerido por SANTOS et al. (2011): diâmetro do halo de inibição do crescimento $\geq 14 \mathrm{~mm}=$ sensível; 9 a $14 \mathrm{~mm}=$ intermediário e $\leq 8 \mathrm{~mm}$ = resistente. Como observado na tabela 1 a FACE e FHM não apresentaram inibição para os fungos ou quando apresentaram foram inferiores ao um diâmetro de $8 \mathrm{~mm}$, sendo considerado ineficiente. O EHEE e FC apresentaram atividade frente a Cladosporium cladosporoides, Aspergilus brasiliensis e Candida albicans com tamanho 8 e 10, 13 e 8, 6 e 9mm respectivamente sendo classificada como intermediário e resistente. A FHX expressou a melhor atividade antifúngica para as cepas testadas, com variação de halo entre 8,00 a 15,00mm, sendo classificada como sensível para Cladosporium cladosporoides, Aspergilus brasiliensis e Candida albicans. Por essa potencialidade dessa fração, fora incorporada a uma microemulsão para melhorar a dispersão cinética dos metabólitos no ágar. A MHX manifestou uma alteração de halo entre 7,2 a 14,8mm, com ação sensível e intermediária e resistente para Aspergilus brasiliensis e Candida albicans.

Tabela 1. Teste qualitativo da Atividade antimicótica dos extratos de Maytenus rígida (medidas em mm).

\begin{tabular}{|c|c|c|c|c|c|}
\hline Extrato & $\begin{array}{c}\text { Cladosporium } \\
\text { cladosporoides }\end{array}$ & $\begin{array}{c}\text { Aspergilus } \\
\text { brasiliensis }\end{array}$ & $\begin{array}{c}\text { Cryptococcus } \\
\text { albidus }\end{array}$ & $\begin{array}{c}\text { Candida } \\
\text { albicans }\end{array}$ & $\begin{array}{c}\text { Aspergillus } \\
\text { niger }\end{array}$ \\
\hline FHX & $10,4 \pm 0,8$ & $15,0 \pm 1,3$ & $8,1 \pm 1,3$ & $15,6 \pm 1,4$ & $8,0 \pm 1,2$ \\
\hline
\end{tabular}




\begin{tabular}{|c|c|c|c|c|c|}
\hline Extrato & $\begin{array}{c}\text { Cladosporium } \\
\text { cladosporoides }\end{array}$ & $\begin{array}{c}\text { Aspergilus } \\
\text { brasiliensis }\end{array}$ & $\begin{array}{c}\text { Cryptococcus } \\
\text { albidus }\end{array}$ & $\begin{array}{c}\text { Candida } \\
\text { albicans }\end{array}$ & $\begin{array}{c}\text { Aspergillus } \\
\text { niger }\end{array}$ \\
\hline EHEE & $8,3 \pm 0,4$ & $13,3 \pm 2,1$ & - & $6,6 \pm 0,8$ & - \\
\hline FC & $10,3 \pm 0,4$ & $8,3 \pm 1,1$ & $5,6 \pm 2,1$ & $9,9 \pm 1,0$ & - \\
\hline FHM & - & - & - & $6,0 \pm 1,0$ & - \\
\hline FACE & $7,3 \pm 0,6$ & - & - & $7,5 \pm 1,2$ & - \\
\hline MHX & $9,8 \pm 1,2$ & $13,6 \pm 2,8$ & $7,2 \pm 1,2$ & $14,8 \pm 1,6$ & $8,2 \pm 1,2$ \\
\hline
\end{tabular}

FHX- Fração hexânica; EHEE - Extrato hidroetanólico da entrecasca; FC - Fração clorofórmica; FHM - Fração hidrometanólica; FACE - Fração acetato de etila; MHX - Microemulsão fração Hexânica

Neste estudo, extratos e frações da M. rigida (EHEE, FAE, FHM, FC e FHX) favoreceram significativamente $(<0,05)$ a viabilidade dos macrófagos $J 774$ em todas as concentrações testadas 30, 100 e 300 $\mu \mathrm{g} \cdot \mathrm{mL}^{-1}$ (Figura 1), em comparação às células não tratadas, as quais funcionaram como controle. Todas as amostras testadas apresentaram comportamento concentração-dependente. A maior viabilidade foi observada no tratamento com FC que com a menor concentração $\left(10 \mu \mathrm{g} \cdot \mathrm{mL}^{-1}\right)$ alcançou o valor de $103,89 \% \pm 5,68$. Nessa mesma fração foi observado o menor resultado com a concentração $300 \mu \mathrm{g} \cdot \mathrm{mL}^{-1}$ que alcançou o valor de $78,33 \% \pm 3,22$. A fração de melhor atividade antimicrobiana foi $F H X$ que não apresentou variação significativa mesmo com a elevação da concentração do extrato e, na concentração de $300 \mu \mathrm{g} \cdot \mathrm{mL}^{-1}$, foi obtido o melhor resultado $98,63 \% \pm 2,08$ de viabilidade celular. Este resultado indica que não há toxicidade dos extratos de $M$. rigida, ou seja, que nenhuma das amostras diminuiu a viabilidade dos macrófagos $\mathrm{J} 774$ em 75\%, valor considerado citotóxico para extratos de plantas (RIBEIRO et al 2012). Por outro lado, NERI-NUMA et al. (2014), afirmam que um extrato que inibe mais de $50 \%$ do crescimento celular e exibe comportamento concentração-dependente é antiproliferativo.

Figura 1. Efeito dos extratos na viabilidade celular determinada pelo ensaio MTT. As amostras foram adicionadas à cultura de macrófagos durante 24 horas. Após este período, adicionou-se solução de MTT a cada poço. Os dados foram reportados como percentagem de controle e expressos como médias \pm desvio padrão. MTT - 3-(4,5-dimetiltiazol-2yl)-2,5-difenil brometo de tetrazolina

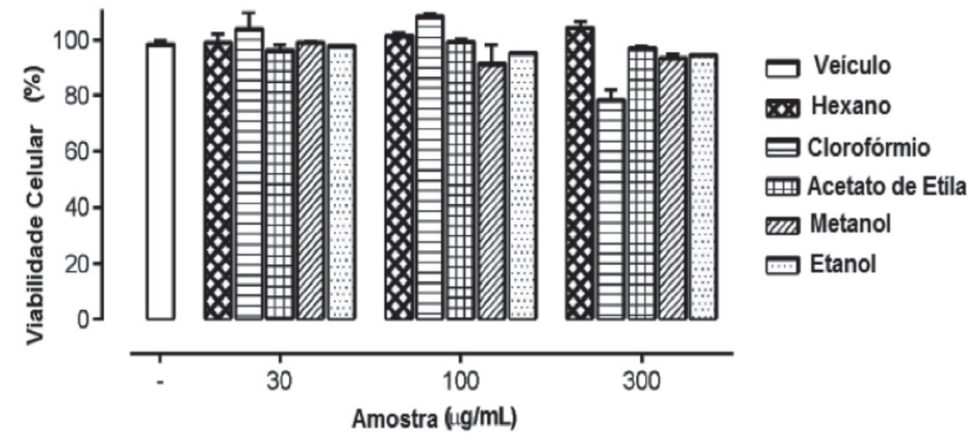




\section{SISTEMAS NANOESTRUTURADOS - MICROEMULSÕES [ME]}

Como demonstra a figura 2 o diagrama de fase ternário (Tween 80, solução tampão fosfato e ácido oleico, $85 \%, 5 \%$ e 10\%, respectivamente) na formulação do ponto B1 está localizado na fase do gráfico pertencente à área identificada como microemulsão, por apresentar melhor solubilidade ao extrato. Neste estudo foram produzidas e caracterizadas duas formulações: ME, $20 \mathrm{~mL}$ e MFHX 10\%, $20 \mathrm{ml}$, para serem testadas em atividades biológicas.

Figura 2. Diagrama Ternário Tampão, Tween 80 e Ác. Oleico.

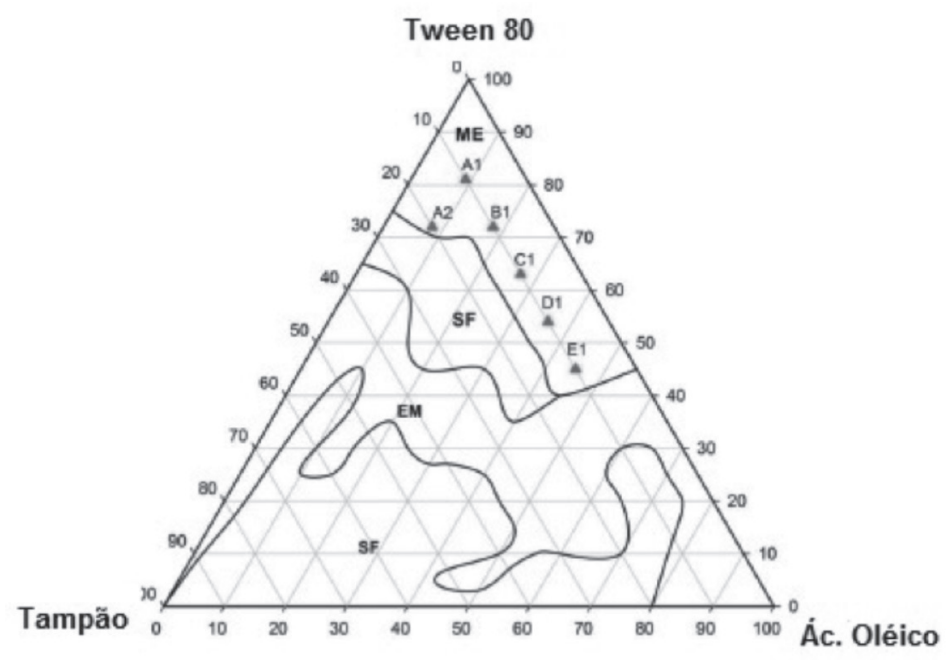

A utilização de veículos para dispersar compostos com atividades farmacológicas é antiga e de grande eficácia, pois diminui a tensão superficial, melhora a permeabilidade e conserva os produtos no local por período maior, além de uma liberação gradativa dos agentes terapêuticos (COSTA et al., 2008). A M. rigida é utilizada popularmente com ação anti-inflamatória, analgésico, cicatrizante, hipotensor, hepatoprotetor, antirreumática, antimicótica e antimicrobiana. Devido às características dos extratos de plantas, a sua incorporação nos sistemas representa um desafio, pela sua insolubilidade tanto em meio aquoso como oleoso. Contudo, alguns trabalhos têm descrito o uso de pH ácido para solubilizar (SILVEIRA, 2009; DAMASCENO et al., 2012). A adição da FHX, fração que nesse estudo apresentou o melhor resultado, às microemulsões reduziu drasticamente a transparência das formulações, situação que foi revertida após adição da solução do $\mathrm{HCl} 1 \mathrm{~N}$ aos sistemas, indicando o favorecimento da incorporação dos extratos. 


\section{CARACTERIZACC̃̃O DAS MICROEMULSÕES}

\section{TAMANHO DE GOTÍCULAS, PH, ÍNDICE DE POLIDISPERSIVIDADE E POTENCIAL ZETA}

A análise do tamanho das gotículas é feita para verificar se as formulações apresentam tamanho manométrico, facilitando a incorporação de moléculas e também facilita a perfusão e dispersão no tecido alvo. 0 índice de polidispersão revela a homogeneidade da população de gotículas, caracterizando uma distribuição de tamanho monomodal ou polimodal (SOARES et al., 2009).

Quanto ao tamanho de gotícula, pode-se observar que ME e MHX 10\% apresentaram diâmetro 20,29 e 18,33nm respectivamente, enquadrando-se nos limites estabelecidos para microemulsões. Diante disso, a mesma e seu veículo, foram submetidos à análise de espalhamento de raios- $X$ a baixo ângulo. SILVA et al. (2014), em estudo de microemulsões com metil dihidrojasmonato, do tipo óleo/água, similar às do presente estudo, obtiveram gotículas de 47,7 a 181,1 nm para as microemulsões sem a presença do metil dihidrojasmonato e àquelas com esta substância incorporada, 11,6 a 82,2 nm.

Com relação ao $\mathrm{pH}$, as formulações descritas anteriormente apresentaram caráter levemente ácido (Tabela 2), ideal para aplicação tópica, dado que o pH da pele oscila entre 4,6-5,8, condição importante para proteção bactericida e fungicida em sua superfície (LEONARDI et al., 2002). Estatisticamente, nenhuma apresentou diferença significativa $(<0,05)$, entre si, em relação a este parâmetro.

Tabela 2. Parâmetros físico-químicos das formulações microemulsão veículo (MV), microemulsão fração hexânica (MHX) da entrecasca da Maytenus rigida 10\% (MHX 10\%).

\begin{tabular}{ccccc}
\hline Formulação & Tamanho de gotícula $(\mathbf{n m})$ & $\mathbf{p H}$ & IPD & PZ (mV) \\
\hline MV & 20,29 & $5,72 \pm 0,24 a$ & 0,25 & $-15,1$ \\
MHX 10\% & 18,33 & $5,50 \pm 0,35 a$ & 0,12 & ND \\
\hline
\end{tabular}

IPD - índice de polidispersividade;

De acordo com a Tabela 2, pode-se também observar que tanto a ME quanto MHX 10\% apresentaram distribuição de tamanho menor que 0,5 para o parâmetro índice de polidispersividade (IPD), denotando homogeneidade na distribuição das gotículas em ambas formulações (SILVA et al., 2014). Encontrou valores de IPD variaram de 0,1 a 0,32 ao estudar microemulsões contendo óleo essencial de Citrus sinensis $L$.

Os sistemas de liberação, ao serem administrados pela via intravenosa, antes de alcançar o sítio-alvo, passam por um processo de biodistribuição, logo após atravessarem as barreiras do epitélio e viajarem pelo leito vascular. A literatura afirma que, após a administração, partículas/gotículas pequenas (>20-30nm) são, quase que prontamente, eliminadas por excreção renal.

\section{MICROSCOPIA DE LUZ POLARIZADA - MLP}

Conforme a MLP, as formulações ME e MHX 10\%, do tipo óleo/água são características de microemulsão, haja visto a presença de campo escuro (CARVALHO et al., 2009), confirmadas pela presença de bolhas, como demonstrado na figura 3. Desse modo, nenhuma delas apresentou desvio ou vibração da luz polarizada. Todas demonstraram as mesmas propriedades ópticas em todas as direções, configurando-se, assim, como estruturas isotrópicas (HYDE, 2001; DJEKIC et al., 2011). 
Figura 3. Fotomicrografias, tiradas com aumento de 100x, representativas de comportamento isotrópico (campo escuro) obtidas das formulações A - Ensaio (tensoativo tween 80, ácido oleico: água), microemulsão veículo (MV), B - Ensaio (tensoativo tween 80, ácido oleico: água) + fração hexânica a $10 \%$ da Maytenus rigida. As setas indicam a presença de bolhas de ar para comprovar o campo escuro.
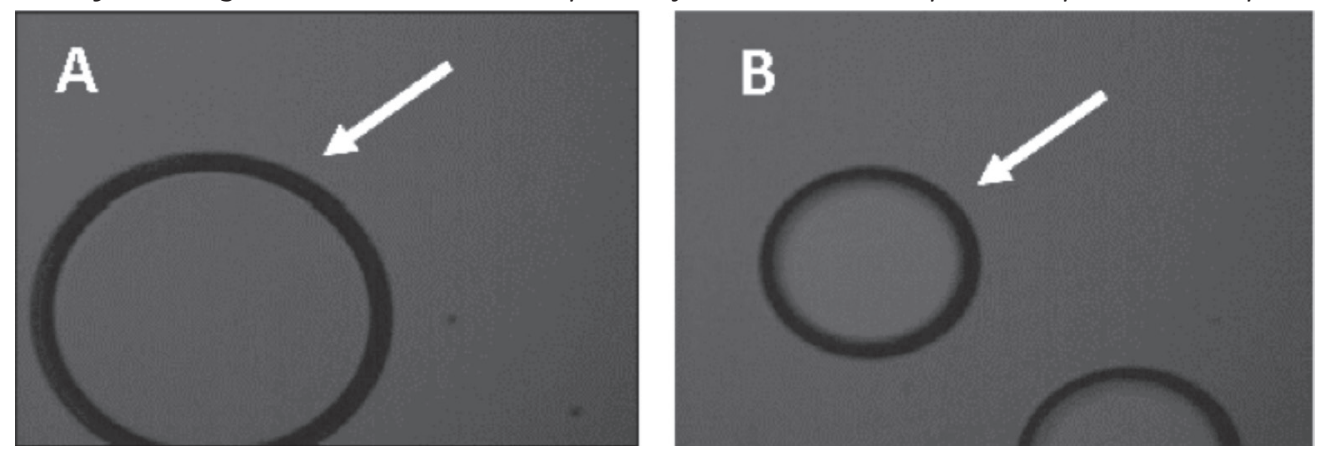

\section{CONCLUSÃO}

$\mathrm{Na}$ análise de compostos químicos, os valores da FACE, FHX, FHM e FC não apresentaram diferenças significativas, comprovando que as frações demonstraram uma grande atividade antioxidante, pois foram observados valores superior a $50 \%$.

Nenhum dos extratos apresentou menos de $75 \%$ de viabilidade à linhagem celular macrófagos J774, efetivando assim a sua aplicação terapeuta.

O EHEE e FC apresentaram atividade frente a Cladosporium cladosporoides, Aspergilus brasiliensis e Candida albicans com halos de tamanho 8 e 10, 13 e 8, 9 e 8, 8 e $8 \mathrm{~mm}$ respectivamente, sendo classificadas como intermediário e resistente. A FHX expressou a melhor atividade antimicrobiana para as cepas testadas, com variação de halo de 8,00 a 15,00mm sendo classificada como sensível para Cladosporium cladosporoides, Aspergilus brasiliensis e Candida albicans.

A MHX apresentou um tamanho de gotícula de $18,33 \mathrm{~nm}$ e IPD de 0,12, se enquadrando em ME com potencial de atividade biológica, além disso apresentou pH 5,50 classificado com levemente ácido, indicado para a utilização tópica desse sistema. A análise de MLP apresenta características isotrópicas de relevância para conservação da sua estrutura e dispersividade dos compostos.

\section{REFERÊNCIAS}

AZMIR, J. et al. Techniques for extraction of bioactive compounds from plant materials: A review. J

Food Eng. v.117, p. 426-436, 2013. 
BACHHAV, Y.G.; PATRAVALE, V.B. Microemulsion based vaginal gel of fluconazole: Formulation, in vitro and in vivo evaluation. Int J Pharm, v. 365, n. 1-2, p. 175-179, 2009.

BAUER, A.W. et al. Antibiotic susceptibility testing by the standardized single disk method. American J Clin Pathol. v. 45, n. 4, p. 493 - 496, 1966.

BITTENCOURT, S.C. et al. O uso das plantas medicinais sob prescrição médica: pontos de diálogo e controvérsias com uso popular. Rev Bras Farmacognos, v. 12, p. 89-91, 2002.

CARVALHO, F.C. et al. LC Evaluation of In Vitro Release of AZT from Microemulsions.

Chromatographia, v. 69, sup. 2, p. 207-211, 2009.

CERA L.F.R. Estudo da incorporação do diclofenaco sódico com microemulsões lipídicas:

formulação e liberação in vitro. 2001. 145f Dissertação (Mestrado) - Universidade Estadual Paulista, Araraquara, 2001.

CLSI - Clinical and Laboratory Standards Institute. Method for antifungal disk diffusion testing of yeast. M44-A. CLSI: Wayne, PA. 2004.

CLSI - Clinical and Laboratory Standards Institute. Methods for Dilution Antimicrobial

Susceptibility Tests for Bacteria That Grow Aerobically; Approved Standard. 6th Edition. . CLSI: Wayne, PA. 2003.

COSTA, P.M. et al. Antiproliferative activity of pristimerin isolated from Maytenus ilicifolia (Celastraceae) in human HL-60 cells. Toxicol in Vitro, v. 22, p. 854-863, 2008.

D'CRUZ, O.J.; UCKUN, F.M. Gel-microemulsions as vaginal spermicides and intravaginal drug delivery vehicles. Contraception, v. 64, n. 2, p. 11-123, 2001

DAMASCENO, B.P.G.L. et al. Microemulsão: um promissor carreador para moléculas insolúveis. Rev Ciên Farmac Bás Apl, v. 32, n. 1, p. 9-18, 2012

DIAS, K.S. et al. Antinociceptive activity of Maytenus rigida stem bark. Fitoterapia, v. 78, n. 7-8, p. 460-464, 2007

DJEKIC, L. et al. Phase behaviour, microstructure and ibuprofen solubilization capacity of pseudoternary nonionic microemulsions. J Mol Liq, v. 160, n. 2, p. 81-87, 2011.

ESTEVAM, C.S. et al. Perfil fitoquímico e ensaio microbiológico dos extratos da entrecasca de 
Maytenus rigida Mart. (Celastraceae). Rev Bras Farmacog, v. 19, n. 1B, p. 299-303, 2009.

HYDE, S.T. Identification of lyotropic liquid crystalline mesophases. In: Holmberg K, ed. Handbook of Applied Surface and Colloid Chemistry.: John Wiley \& Sons: New York, 2001.

LEONARDI, G.R. et al. Estudo da variação do pH da pele humana exposta à formulação cosmética acrescida ou não de vitaminas A, E ou de ceramida, por metodologia não invasiva. An Bras Dermatol, v. 77, p. 563-569, 2002.

MARTUCCIELLO, S. et al. Effects of triterpene derivatives from Maytenus rigida on VEGF-induced Kaposi's sarcoma cell proliferation. Chem-Biol Interact, v. 183, p. 450-454, 2010.

MEHTA, S.K. et al. Analysis of Tween based microemulsion in the presence of TB drug rifampicin. Coll Surf B: Biointerf, v. 60, p. 95-104, 2007.

MOLINARI, G. Natural products in drug discovery: present status and perspectives. Pharm Biotec Adv Exp Med Biol, v. 655, p. 13-27, 2009.

MOSMANN T. Rapid colorimetric assay for cellular growth and survival: application to proliferation and cytotoxicity assays. J Immunol Method, v.65. p. 55-63, 1983.

NERI-NUMA, I.A. et al. Preliminary evaluation of antioxidant, antiproliferative and antimutagenic activities of pitomba (Talisia esculenta). Food Sci Technol, v. 59, n. 2, Part 2, p. 1233-1238, 2014,

OMENA, M.L.R.A. Ensaio etnofarmacológico de espécies vegetais com ação no sistema nervoso central, originárias do bioma caatinga. Saúde Amb Rev, v. 2, p. 92-107, 2007.

PIRES, I.F.B. et al. Plantas medicinais como opção terapêutica em comunidade de Montes Claros, Minas Gerais, Brasil. Rev Bras PI Med, v. 16, n. 2, p. 426-433, 2014.

REINALDO, R.C.P.S. et al. Do ferns and lycophytes function as medicinal plants? A study of their low representation in tradicional pharmacopoeias. J Ethnopharmacol, v. 175, p.39-47, 2015.

RIBEIRO, A.F.C. Avaliação das atividades anti-inflamatória, antiangiogênica e antitumoral de extratos da Arrabidaea chica (Humb. \& Bonpl.) B. Verlot. 2012. 92 f., Tese (Doutorado) Universidade Federal de Minas Gerais, Belo Horizonte, 2012.

SANTOS, V.L. et al. Pharmacological studies of ethanolic extracts of Maytenus rigida Mart (Celastraceae) in animal models. Rev Bras Farmacog, v. 17, p. 336-342, 2007 
SANTOS, V.L. et al. Avaliação da atividade antimicrobiana de Maytenus rigida Mart. (Celastraceae). Rev Bras Pl Med, v.13, n.1, p.68-72, 2011.

SILVA, G.B.R.F. et al. Development and characterization of biocompatible isotropic and anisotripic oil-inwater coloidal dispersions as a new delivery system for methyl dihydrojasmonate antitumor Drug. Int J Nanomedic, v. 9, p. 867-876, 2014.

\section{SILVEIRA, L.L. Desenvolvimento e caracterização} de um sistema microemulsionado contendo Anfotericina B para uso oftalmológico. 2009, 65f. Dissertação (Mestrado) - Universidade Federal de Rio Grande do Norte, Natal, 2009.

SOARES, L.A.L. et al. Developmet and validation of a LC-method for determination of catechin and epicatechin in aqueous extractives from leaves of Maytenus ilicifolia. J Pharm Biomed Anal, v. 36, p. 787-790, 2009.
Recebido em: 13 de Março de 2019

Avaliado em: 19 de Maio de 2019

Aceito em: 19 de Maio de 2019

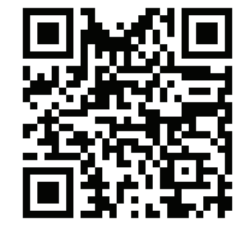

A autenticidade desse artigo pode ser conferida no site https://periodicos. set.edu.br

1 Discente do Curso Superior em Tecnologia em Alimentos. Instituto Federal Educação, Ciência e Tecnologia de Sergipe - IFS, Aracaju, SE. Bolsista de IC IFS.

E-mail: mayaratavaresrad@gmail.com

2 Doutor em Engenharia de Processos pela Universidade Tiradentes, Docente do Programa de Pós-graduação Mestrado Profissional em Educação Profissional e Tecnológica (ProfEPT), Instituto Federal Educação, Ciência e Tecnologia de Sergipe - IFS, Aracaju, SE.

E-mail: reisigoradriano@gmail.com

3 Doutor em Biotecnologia pela Universidade Federal de Sergipe - UFS, São Cristóvão, SE.

E-mail: samuelbruno@gmail.com 